\title{
Anatomical Study of the Superficial Palmar Arch, its Relation to the Kaplan Cardinal Line and Literature Review
}

\section{Estudio anatómico del arco palmar superficial, su relación con la línea cardinal de Kaplan y revisión de la literatura}

\author{
Claudia Arroyo Berezowsky ${ }^{1}$ Alejandro Espinosa Gutiérrez ${ }^{2}$ jimena Quinzaños Fresnedo ${ }^{3}$ \\ José Antonio Rivas Montero² \\ ${ }^{1}$ Orthopedics and Hand Surgery, Instituto Nacional de Rehabilitación \\ Luis Guillermo Ibarra Ibarra, Ciudad de México, Mexico \\ ${ }^{2}$ Hand Service, Instituto Nacional de Rehabilitación Luis Guillermo \\ Ibarra Ibarra, Ciudad de México, Mexico \\ ${ }^{3}$ Nuerological Rehabilitation Division, Instituto Nacional de Rehabilitación \\ Luis Guillermo Ibarra Ibarra, Ciudad de México, Mexico \\ Address for correspondence Claudia Arroyo Berezowsky, MD, \\ Cirugía de Mano, Instituto Nacional de Rehabilitación Luis Guillermo \\ Ibarra Ibarra, Calz México-Xochimilco 289, Arenal Tepepan, \\ 14389 Ciudad de México, CDMX, $7^{\circ}$ piso Ortopedia, México \\ (e-mail: dra.carroyob@gmail.com).
}

Rev Iberam Cir Mano 2018;46:96-105.

\begin{abstract}
Keywords

- superficial palmar arch

- hand

- vascularity
\end{abstract}

Introduction The superficial palmar arch is the main contributor to the vascular supply of the hand. Numerous anatomical variants have been described and there are multiple classifications of the superficial palmar arch available. The Kaplan cardinal line is used occasionally as a reference to identify the deep structures of the hand. However, there are also multiple variants of the line and multiple reports regarding the structures that can be identified with it.

Material and Methods Ten anatomical dissections of hands were performed in seven cadaveric specimens. The anatomical variants of the superficial palmar arch were recorded, as well as their relationship with the Kaplan cardinal line. A review of the available literature was made.

Results According to the classification by Coleman et al, the most common type was the complete superficial palmar arch, present in seven hands, while the incomplete superficial palmar arch was found in three hands. The most frequent complete palmar arch was type IB, followed by type IIB, and finally type IA and type IIA. The most common relation was with the Kaplan cardinal line type $A$ to the apex of the arch and with type $B$ to the curvature of the ulnar artery.

Conclusions There is a great anatomical variability in the superficial palmar arch. There was a greater frequency of the complete superficial palmar arch, with the ulnar artery being the dominant vascular supply. The Kaplan cardinal line can be used as a safety limit to avoid the superficial palmar arch if it is drawn to intersect the pisiform bone.

Clinical Relevance It is important to be aware of the anatomical variants of the superficial palmar arch, as well as of its relationship with the superficial structures of the hand to be able to perform invasive or reconstructive procedures and to preserve the vascularity of the hand. received

April 29, 2018

accepted

October 10, 2018
DOI https://doi.org/

10.1055/s-0038-1676046. ISSN 1698-8396.
Copyright $\odot 2018$ Thieme Revinter

Publicações Ltda, Rio de Janeiro, Brazil
License terms

(c) $(1) \$$ 


\section{Resumen}

\section{Palabras Clave \\ - arco palmar superficial \\ - mano \\ - vascularidad}

Introducción El aporte vascular de la mano está dado principalmente por el arco palmar superficial. Se han descrito numerosas variantes anatómicas del arco palmar superficial y existen múltiples clasificaciones en la literatura mundial. La línea cardinal de Kaplan es utilizada en ocasiones como referencia para identificar estructuras profundas en la mano, sin embargo, también existen múltiples variantes y discrepancia en sus relaciones con las estructuras profundas de la mano.

Material y Método Se realizaron diez disecciones anatómicas en siete especímenes cadavéricos. Se identificaron las variantes anatómicas del arco palmar superficial y su relación con cuatro variantes descritas de la línea de Kaplan, se realizó una revisión de la literatura.

Resultados De acuerdo a la clasificación de Coleman \& Anson fue más común el arco palmar completo ( 7 casos) que el incompleto ( 3 casos). El tipo más frecuente de arco palmar superficial completo el tipo IB, seguido del tipo IIB y al final el tipo IA y el tipo IIA. La línea de Kaplan con más relación con el arco palmar fue la tipo $B$ en la curvatura y con la línea $\mathrm{A}$ en el ápice. Existe discrepancia en la frecuencia del tipo de arco palmar superficial dependiendo de la clasificación utilizada.

Conclusiones Existe gran variabilidad anatómica en el arco palmar superficial. Hubo una mayor frecuencia de arco palmar superficial completo y el predominio de aporte vascular fue de la arteria cubital. La línea cardinal de Kaplan puede servir como un límite de seguridad para evitar el arco palmar superficial si se traza hacia el hueso pisiforme. Importancia Clínica: Se deben conocer las variantes anatómicas del arco palmar superficial y su relación con las estructuras superficiales de la mano para realizar procedimientos quirúrgicos en la mano.

\section{Introduction}

The vascular pattern of the hand has been widely studied because of its great anatomical variability. The emergence of more advanced reconstructive and microsurgical techniques, as well as the use of vascular access and radial artery grafts in cardiac revascularization procedures, has seen a renewed interest in the vascular supply of the hand. ${ }^{1}$

The superficial palmar arch has been classically described as an anastomosis between the radial artery and the ulnar artery, predominantly supplied by the latter. The ulnar artery enters the palm of the hand along with the ulnar nerve, superficial to the flexor retinaculum, radial to the pisiform bone and ulnar to the hook of the hamate bone, within the Guyón canal. It curves radially to form a convex arc distally parallel to a transverse line drawn from the first interdigital space with the thumb in full extension. The superficial palmar arch is covered by the palmaris brevis muscle and by the palmar aponeurosis. It is superficial to the flexor digiti minimi muscle, to the branches of the median nerve, to the long flexor tendons of the triphalangeal fingers and to the lumbrical muscles. ${ }^{1}$ There are significant anatomical variants of the superficial palmar arch, in which there may be supply from an embryological remnant known as the median artery, with or without an anastomosis between the radial and the ulnar artery, among other possibilities.

The first known description of the complete or incomplete superficial palmar arch was made by Jachtischinski in
1897. ${ }^{2,3}$ A complete palmar arch was defined as when there is an anastomosis between the vessels that form it, and an incomplete one as when there is no anastomosis of different vessels. ${ }^{4,5}$ A complete palmar arch was also considered to be an arch in which the ulnar artery supplies the thumb, while an arch was considered as incomplete when the ulnar artery does not reach the first interdigital space. ${ }^{2,5,6}$ Other studies on the superficial palmar arch published subsequently were: Adachi, in $1928 ;^{7}$ Coleman et al, in $1961 ;^{8}$ Lippert et al, in $1985 ;{ }^{9}$ Jelicic et al, in $1988 ;{ }^{7}$ Ikeda et al, in $1988 ;{ }^{10}$, Özkus et al, in $1998 ;{ }^{11}$ Gellman et al, in $2001 ;^{5}$ Loukas et al, in $2005 ;{ }^{12}$ Tagil et al, in 2007; ${ }^{13}$ Bataineh et al, in 2009; ${ }^{14}$ and Feigl et al, in 2012. ${ }^{15}$ Many of these studies proposed new classifications of the morphology of the superficial palmar arch, which has complicated the development of a universal classification and has led to differences in the frequency of certain types of palmar arch. Likewise, some authors defined the type of palmar arch depending on the radial artery, ulnar artery or the median artery supply, while others defined the type of palmar arch depending on the common or specific digital palmar arteries that derived from the arch. The most commonly used classifications in the literature are the one by Jaschtschinski ${ }^{2,3}$ (-Table 1 ), its modification by Coleman et al ( $\mathbf{- T a b l e ~ 2 )}$ ), and that by Lippert et $\mathrm{al}^{9}$ ( $\mathbf{-}$ Table $\mathbf{3}$ ).

In these three classifications, there are important variations that can make the difference in the frequency of complete or incomplete palm arches. ${ }^{15}$ The classification by Jaschtcschinski ${ }^{2}$ and that by Coleman et $\mathrm{al}^{8}$ consider a complete palmar arch as 
Table 1 Types of superficial palmar arch according to Jaschtschinski ${ }^{2}$

\begin{tabular}{|c|c|c|c|c|c|}
\hline Group & A & B & C & D & $E$ \\
\hline $\begin{array}{l}\text { Complete } \\
\text { palmar } \\
\text { arch I }\end{array}$ & $\begin{array}{l}\text { Radio-ulnar type } \\
\text { Anastomosis between } \\
\text { the ulnar artery and the } \\
\text { superficial branch of the } \\
\text { radial artery }\end{array}$ & $\begin{array}{l}\text { Type median-ulnar } \\
\text { Anastomosis between } \\
\text { the ulnar artery and the } \\
\text { median artery }\end{array}$ & $\begin{array}{l}\text { Radial-median ulnar } \\
\text { Anastomosis between } \\
\text { the ulnar artery, the } \\
\text { median artery, and the } \\
\text { superficial branch of } \\
\text { the radial artery }\end{array}$ & $\begin{array}{l}\text { Ulnar } \\
\text { Ulnar artery reaches } \\
\text { the radial border of } \\
\text { the thumb }\end{array}$ & $\begin{array}{l}\text { Radial-median } \\
\text { Anastomosis between } \\
\text { median artery and } \\
\text { superficial branch of } \\
\text { radial artery }\end{array}$ \\
\hline $\begin{array}{l}\text { Incomplete } \\
\text { palmar } \\
\text { arch II }\end{array}$ & $\begin{array}{l}\text { Without anastomosis. } \\
\text { No median or superfi- } \\
\text { cial radial artery. } \\
\text { The carpal branch of the } \\
\text { ulnar artery gives rise to } \\
\text { three common digital } \\
\text { palmar arteries and } \\
\text { artery digitalis } \\
\text { palmaris propria ulnaris } \\
\text { to the fifth digit }\end{array}$ & $\begin{array}{l}\text { Without anastomosis. } \\
\text { No median or superfi- } \\
\text { cial radial artery. } \\
\text { Equal to type IIA but the } \\
\text { ulnar artery leads to the } \\
\text { radialis indicis artery. }\end{array}$ & $\begin{array}{l}\text { Without anastomosis } \\
\text { between arteries. } \\
\text { Superficial artery of } \\
\text { the radialis indicis } \\
\text { artery. } \\
\text { Remainder by the } \\
\text { ulnar artery like IIA. }\end{array}$ & $\begin{array}{l}\text { Without anastomosis. } \\
\text { The carpal branch of } \\
\text { the ulnar artery leads } \\
\text { to the } \\
\text { common second and } \\
\text { third digital arteries } \\
\text { and to the proper } \\
\text { palmar digital artery } \\
\text { of the fifth digit. The } \\
\text { superficial branch of } \\
\text { the radial radialis indi- } \\
\text { cis artery and the digi- } \\
\text { talis palmaris comunis } \\
\text { primus }\end{array}$ & \\
\hline
\end{tabular}

Table 2 Types of superficial palmar arch according to Coleman \& Anson ${ }^{8}$

\begin{tabular}{|l|l|l|l|l|}
\hline Grupo & A & B & C & D \\
\hline $\begin{array}{l}\text { Complete } \\
\text { palmar } \\
\text { arch I }\end{array}$ & $\begin{array}{l}\text { Ulnar-radial } \\
\text { Superficial palmar } \\
\text { branch of the radial artery }+ \\
\text { dominant ulnar artery }\end{array}$ & $\begin{array}{l}\text { Ulnar } \\
\text { Ulnar artery only }\end{array}$ & $\begin{array}{l}\text { Median-ulnar } \\
\text { Ulnar artery }+ \\
\text { median artery }\end{array}$ & $\begin{array}{l}\text { Radial-median-ulnar } \\
\text { Radial-median-ulnar } \\
\text { arch }\end{array}$ \\
\hline $\begin{array}{l}\text { Incomplete } \\
\text { palmar } \\
\text { arch II }\end{array}$ & $\begin{array}{l}\text { Superficial palmar } \\
\text { branch of the radial artery }+ \\
\text { ulnar artery }\end{array}$ & $\begin{array}{l}\text { Ulnar artery only } \\
\text { (does not reach } \\
\text { the thumb or the } \\
\text { index finger) }\end{array}$ & $\begin{array}{l}\text { Superficial vessels } \\
\text { of the median artery } \\
\text { ulnar artery } \\
\text { vessel from deep } \\
\text { palmar arch }\end{array}$ & $\begin{array}{l}\text { Superficial vessels of } \\
\text { the radial, the median, } \\
\text { and the ulnar artery }\end{array}$ \\
\hline
\end{tabular}

Table 3 Types of superficial palmar arch according to Lippert \& Pabst ${ }^{9}$

\begin{tabular}{|c|c|c|c|c|c|}
\hline Group & 1 & 2 & 3 & 4 & 5 \\
\hline $\begin{array}{l}\text { Complete } \\
\text { palmar } \\
\text { arch A }\end{array}$ & $\begin{array}{l}\text { Classic radial-ulnar arch } \\
\text { Anastomosis between the } \\
\text { ulnar artery and the } \\
\text { superficial branch of } \\
\text { the radial artery }\end{array}$ & $\begin{array}{l}\text { Median-ulnar arch } \\
\text { Anastomosis between } \\
\text { the ulnar artery and } \\
\text { the median artery }\end{array}$ & $\begin{array}{l}\text { Radial-median-ulnar } \\
\text { arch } \\
\text { With anastomosis } \\
\text { between the median, } \\
\text { the radial and the } \\
\text { ulnar artery }\end{array}$ & $\begin{array}{l}\text { Deep ulnar arch } \\
\text { Anastomosis between } \\
\text { the ulnar artery and } \\
\text { the deep branch of } \\
\text { the radial artery as } \\
\text { the first dorsal } \\
\text { interosseous artery }\end{array}$ & $\begin{array}{l}\text { Median-radial arch } \\
\text { Anastomosis between } \\
\text { the median and the } \\
\text { superficial radial } \\
\text { artery }\end{array}$ \\
\hline $\begin{array}{l}\text { Incomplete } \\
\text { palmar } \\
\text { arch B }\end{array}$ & $\begin{array}{l}\text { Ulnar } \\
\text { Ulnar artery forms an arch } \\
\text { without anastomosis to } \\
\text { another artery } \\
\text { B1a: branches to the } \\
\text { ulnar border of the thumb } \\
\text { B1b: no ulnar supply } \\
\text { to the thumb }\end{array}$ & $\begin{array}{l}\text { Radial and ulnar } \\
\text { artery } \\
\text { Reach the palm } \\
\text { and provide } \\
\text { branches to the } \\
\text { fingers }\end{array}$ & $\begin{array}{l}\text { Ulnar and median } \\
\text { artery } \\
\text { Reach the palm and } \\
\text { provide branches } \\
\text { to the fingers }\end{array}$ & $\begin{array}{l}\text { Ulnar, medial and } \\
\text { radial artery } \\
\text { Reach the palm and } \\
\text { provide branches } \\
\text { to the fingers }\end{array}$ & \\
\hline
\end{tabular}

one in which the ulnar artery supplies vascularity to the index finger and to the thumb, even if there is no anastomosis with another vessel (either with the radial or with the median artery). ${ }^{8,15,16}$ On the other hand, the classification by Lippert et al considers the palmar arch with supply only from the ulnar artery (even to the thumb) as incomplete. In addition, it subdivides this type of arch depending on the last finger to which the ulnar artery provides vascularity (either the thumb or the index finger). ${ }^{9,15,16}$ This small difference can affect up to
$40 \%$ of the frequency of complete or incomplete superficial palmar arches. ${ }^{15}$ For its part, the classification by Jaschtcschin$\mathrm{ski}^{2}$ subdivides the incomplete palmar arch depending on the last artery supplied by the ulnar artery. ${ }^{15}$ The classification by Coleman et $\mathrm{al}^{8}$ subdivides the incomplete palmar arches depending on the arterial supply received by each side. It considers as a variant of the incomplete ulnar arch those cases in which the ulnar artery does not reach the thumb or the forefinger ( - Table 4$)^{8}$ 
Table 4 Comparison of superficial palmar arch classifications

\begin{tabular}{|c|c|c|c|}
\hline & Jaschtcschinski $^{2}$ & $\begin{array}{l}\text { Lippert } \\
\text { et } \mathrm{al}^{9}\end{array}$ & $\begin{array}{l}\text { Coleman } \\
\text { et al }{ }^{8}\end{array}$ \\
\hline $\begin{array}{l}\text { Complete } \\
\text { radial-ulnar }\end{array}$ & IA & $\mathrm{A} 1$ & IA \\
\hline $\begin{array}{l}\text { Complete } \\
\text { median- } \\
\text { ulnar }\end{array}$ & IB & A2 & IC \\
\hline Complete & IC & A3 & ID \\
\hline $\begin{array}{l}\text { Radial- } \\
\text { median- } \\
\text { ulnar }\end{array}$ & ID & B1a & IB \\
\hline $\begin{array}{l}\text { Complete } \\
\text { ulnar }\end{array}$ & $\mathrm{IIA} / \mathrm{IIB}^{*}$ & B1b & IIB \\
\hline
\end{tabular}

*difference depending on the last artery the ulnar artery supplies. Comparison of the most frequently used classifications of the superficial palmar arch. We can observe how all classifications incorporate the same type of superficial palmar arch but change its name.

With the emergence of endoscopic and open carpal tunnel releases, anatomical relationships of the surface structures with the deep structures of the hand have been sought. In 1953, Kaplan made the first description of the cardinal line of the hand drawn from the apex of the interdigital crease between the thumb and the forefinger towards the ulnar edge of the hand, parallel to the middle palmar crease of the hand. ${ }^{17}$ There are two other descriptions by Kaplan, one from 1965 that describes the cardinal line as reaching the intersection with the metacarpophalangeal crease of the thumb, ${ }^{18}$ and another published in 1968, at $2 \mathrm{~cm}$ from the pisiform bone. ${ }^{19}$ Brown et al described a fourth variant from the first interdigital space to the hook of the hamate bone. ${ }^{20}$ In the Instituto Nacional de Rehabilitación, the Kaplan cardinal line is used as a reference and as a distal limit for safe endoscopic and open carpal tunnel releases. However, there is no consensus in the anatomical references as to how it should be drawn.

The objectives of the present study are to understand the frequency of the different types of superficial palmar arches, to describe the observed anatomical variants of the superficial palmar arch, and to describe the relation of the superficial palmar arch with any of the four variants of the Kaplan cardinal line.

\section{Material and Methods}

Ten dissections were performed in 7 anonymous cadavers at the National Institute of Forensic Sciences under the authorization protocol SIE/DIS/053/2017. The inclusion criteria for the selection of the specimens included any male or female cadaver $>18$ years old granted by the National Institute of Forensic Sciences. The exclusion criteria were evidence of injuries to the palm of the hand or scars on the palm of the hand.

The independent variables recorded were: age, gender, dissected side, type of palmar arch, and the Kaplan cardinal line that corresponded to the start of the curve of the superficial palmar arch.

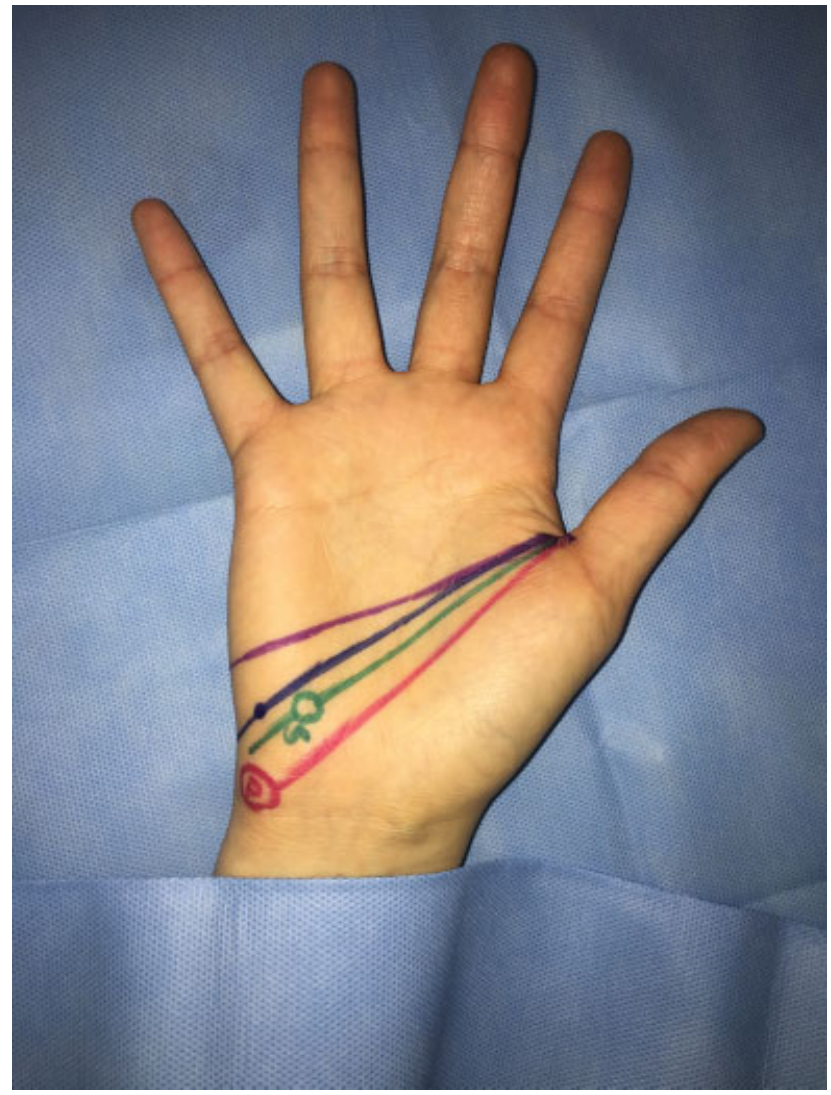

Fig. 1 Variants of the Kaplan cardinal line. Violet: original description (Line A). Blue: intersection $2 \mathrm{~cm}$ distal to the pisiform body (Line B). Green: intersection with the hamate bone hook. The hook is marked and identified with a $G$ (Line C). Pink: Intersection with the pisiform bone. Line on thumb abduction axis. The pisiform bone is marked with a $\mathrm{P}$ (Line D).

Before beginning the dissection, the face of the cadaverous specimen was covered and the hand to be worked on was isolated with a clean cloth. The pisiform bone and the hamate hook were identified. With a violet marker, the four variants of the Kaplan cardinal line were marked on the skin. The four variants originated in the first palmar interdigital space with the thumb in abduction and were drawn as follows (-Fig. 1):

- Line A: parallel to the middle palmar crease

- Line B: intersection with a point $2 \mathrm{~cm}$ distal of the pisiform bone

- Line C: intersection with the hook of the hamate bone

- Line D: a line on the abduction axis of the thumb intersecting the pisiform bone

Methyl methacrylate was injected twice with red staining in the brachial artery to plasticize the vessels. No polymer was used in the rest of the dissections, for logistical reasons. For the dissection, the skin was elevated along with the palmar fascia and the palmaris longus from the proximal palmar crease of the wrist to the metacarpophalangeal joint and the palmar arch, exposing the common digital arteries along with the common digital nerves. Neither the muscles of the thenar region nor those of the hypothenar region were mobilized. The superficial palmar arches were documented 
with photographs, the type of palmar arch was classified according to the classification by Coleman et $\mathrm{al}^{8}{ }^{8}$ and it was observed which of the four variants of the Kaplan cardinal line corresponded to the start of the curve of the palmar arch of the ulnar side and which of the four variants of the Kaplan cardinal line corresponded to the apex of the superficial palmar arch.

The frequency of each type of superficial palmar arch was calculated according to the classification by Coleman et al, ${ }^{8}$ as well as the frequency of complete and incomplete arches. Finally, the palmar arches were classified according to Lippert et $\mathrm{al}^{9}$ and to Jaschtschinski, ${ }^{2}$ and the frequency and percentage of complete and incomplete superficial palmar arches were calculated again, as well as the ulnar arches, in order to determine if there was a difference in the frequencies of arch types according to the different classifications.

The results can be seen in - Table 4. Ten dissections were performed in 7 cadavers, all male, with an average age of 35.5 years old, on 5 right hands and 5 left hands. In three cases, a bilateral dissection was performed.

\section{Results}

Seven complete superficial and three incomplete superficial palmar arches were found. According to the classification by Coleman et al, $^{8}$ the most frequent type of complete superficial palmar arch was ulnar type IB (complete ulnar arch), present in six of the specimens, three right hands and three left hands (- Picture 1). The second most common type was type IIB (ulnar artery without supply to the index finger or to

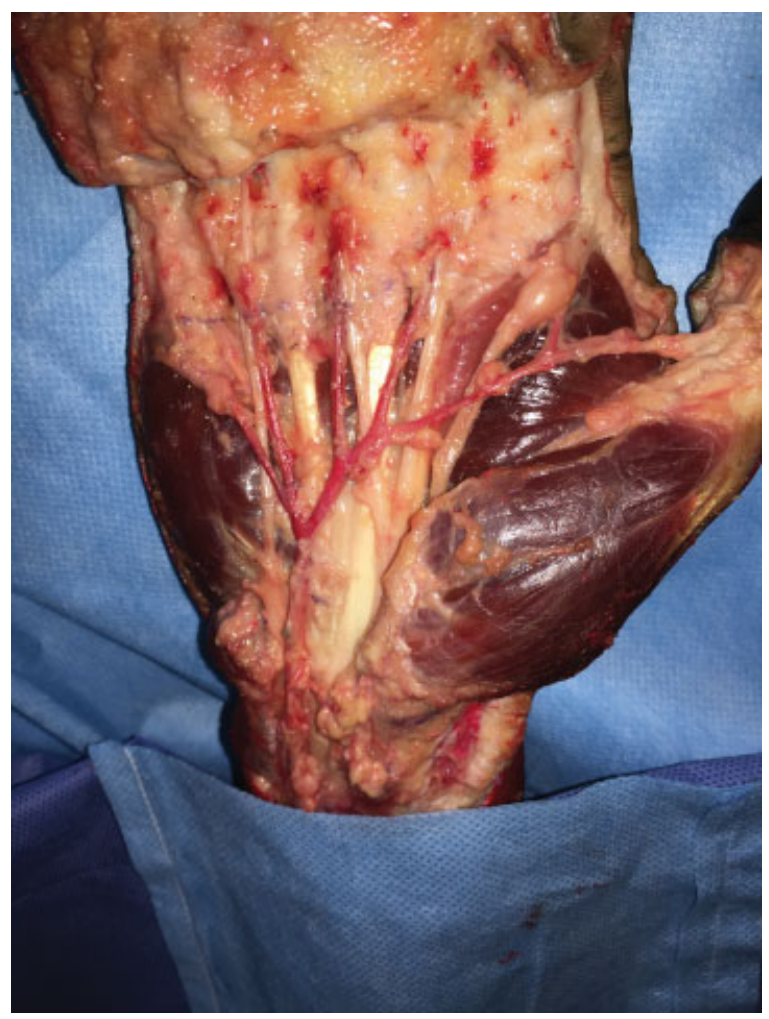

Picture 1 Right hand with polymer, complete ulnar arch to the thumb IB.

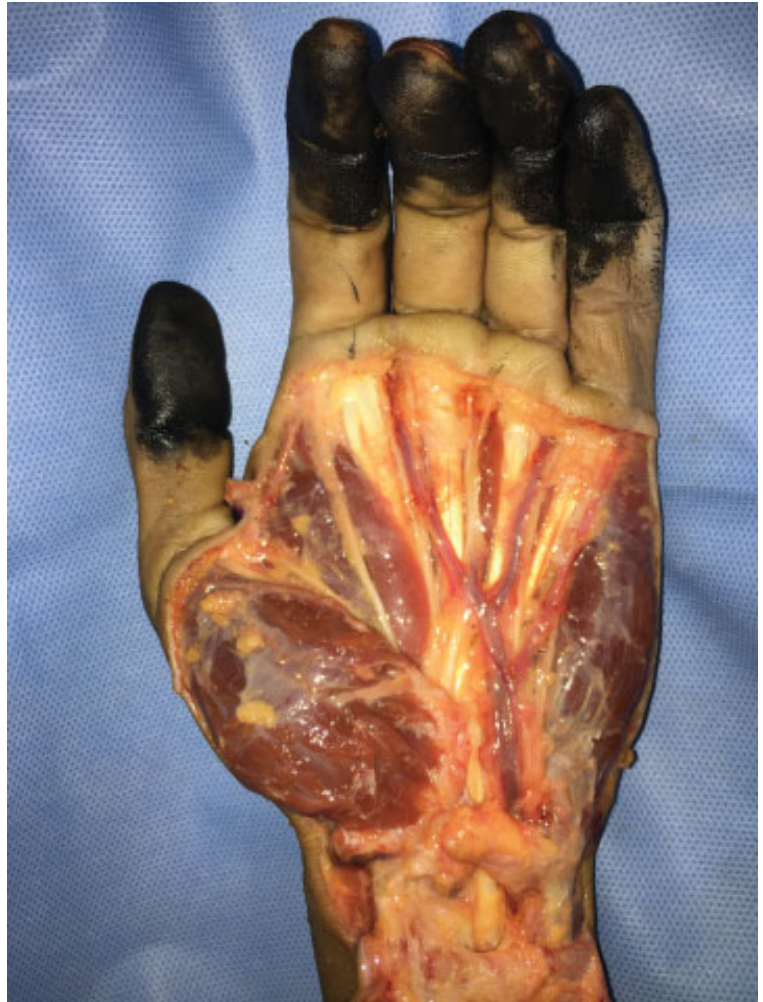

Picture 2 Left Hand. Incomplete superficial palmar arch IIB (ulnar artery supply to the ulnar border of the index finger). No superficial branch of radial artery supply is noted on the muscles of the thenar region.

the thumb) in two of the cases, one in the right hand and the other in the left hand, both in the same subject (-Picture 2). Type IA (considered the classical type) was present in one left hand ( - Picture 3 ), and type IIA (incomplete, with supply of superficial branch of radial artery and ulnar artery) in one right hand. Seven of the palmar arches were complete and the rest incomplete (-Table $\mathbf{5}$ ).

When reclassifying according to the classification by Jaschtschinski ${ }^{2}$, seven of the superficial palmar arches were complete and the rest incomplete. Of these, six of the arches were of ulnar supply (all complete). According to the classification by Lippert et $\mathrm{al}^{9}{ }^{9}$ nine of the palm arches were incomplete and, of those, eight had ulnar supply; six had supply from the ulnar artery to the thumb (type B1a), and two had no supply from the ulnar artery to the thumb (type B1b).

The type of Kaplan cardinal line with which the start of the curve of the palmar arch most frequently coincided was type $\mathrm{B}$ (intersection with a point $2 \mathrm{~cm}$ distal to the pisiform bone), observed in five of the cases. Three of the specimens corresponded to type $\mathrm{C}$ (intersection with the hook of the hamate bone), two corresponded to the original description of the Kaplan cardinal line and never coincided with line A (intersection with the pisiform bone). The line that most frequently coincided with the apex of the arch was line $A$, in eight cases, and line B, in two cases.

- Table 6 shows the different ways of classifying the superficial palmar arches used in the present study (Coleman et al, ${ }^{8}$ Jaschtschinski, ${ }^{2}$ and Lippert et $\mathrm{al}^{9}$ ). - Table 7 shows the 


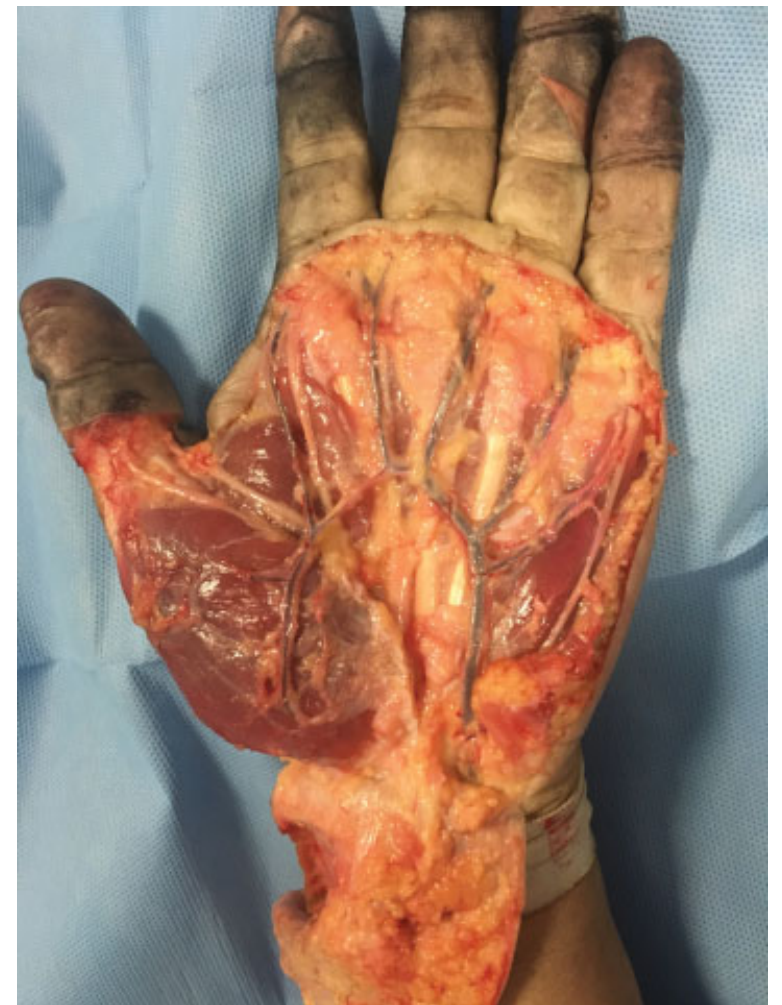

Picture 3 Left hand. Classic complete palmar arch IA. With anastomosis between the radial and the ulnar artery.

frequency between the different subtypes of palmar arches depending on the classification used. - Table 8 shows the frequency of complete, incomplete, and ulnar type superficial palmar arch, depending on the classification used.

\section{Discussion}

In a review of the literature, Arias-Hernández et al ${ }^{16}$ found that of 3,073 hands studied, 1,731 (56.65\%) were complete palmar arches, and 1,342 (43.35\%) were incomplete palmar arches according to the classification by Lippert et al. $^{9}$ The most common type of complete palmar arch was type A1 (radioulnar anastomosis), observed in 664 (64\%) specimen hands. The most common type of incomplete superficial palmar arch was type B1a (ulnar artery with supply to the thumb), with 516 specimens ( $48.80 \%$ ), followed by type B1b, with 342 specimens (32.40\%). In total, $81.2 \%$ of the incomplete palmar arches were ulnar palmar arches. ${ }^{16}$ Regarding the superficial palmar arch with ulnar supply, Suman et $\mathrm{al}^{6}$ consider that its frequency is underestimated. He described a $50 \%$ frequency of complete superficial palmar arches formed solely by the ulnar artery in 60 corpses in India. ${ }^{6}$ Other authors who have reported a lower frequency of ulnar dominant complete superficial palmar arches were: Jachtischinski (38\%), ${ }^{2}$ Coleman et al $(37 \%),{ }^{8}$ Gellman et al (31\%), ${ }^{5}$ Showri et al (40\%), ${ }^{21}$ Earley (20\%), ${ }^{22}$ Ikeda et al (25.5\%), ${ }^{10}$ Al-Turk et al (8\%), ${ }^{23}$ and Patnaik et al (2\%). ${ }^{24}$

- Table 9 shows a review of the literature and an adaptation of previous reviews that includes different anatomical studies of the superficial palmar arch. The percentage of complete and incomplete superficial palmar arches and the classification used by the authors is included, as well as the frequency of the ulnar palmar arch. Twenty-one studies were included, all of which involved studying more than 20 palm arches.

We can observe that most of the studies use the classifications by Jaschtschinski, ${ }^{2}$ by Lippert et al, ${ }^{9}$ or by Coleman et al. ${ }^{8}$ Those who made modifications and proposed a new classification were generally based on the classification by Jaschtschinski. ${ }^{2}$ Some anatomical studies do not specify the superficial palmar arch classification used. ${ }^{1,15,16}$ Some studies do not report the percentage of ulnar palmar arches found, reporting only if they were complete or incomplete. In other cases, the authors do not specify whether the ulnar palmar arch percentage is part of the total specimens or a percentage of the complete or incomplete arches. There are studies that do not subclassify palmar arch types, mentioning only the frequency of the complete or incomplete superficial palmar arch type. We can see that the studies using the classification by Lippert et $\mathrm{al}^{9}$ report a higher frequency of incomplete superficial palmar arches when there is a high

Table 5 Demographics

\begin{tabular}{|l|l|l|l|l|l|}
\hline Age & Gender & Hand & $\begin{array}{l}\text { Palmar Arch Type } \\
\text { (Coleman \& Anson) }\end{array}$ & $\begin{array}{l}\text { Kaplan cardinal line curve } \\
\text { (start of curve) }\end{array}$ & $\begin{array}{l}\text { Kaplan cardinal line } \\
\text { (apex of arch) }\end{array}$ \\
\hline 28 & M & Right & IB & B & A \\
\hline 48 & M & Right & IIA & B & A \\
\hline 48 & M & Left & IA & A & A \\
\hline 29 & M & Left & IB & C & A \\
\hline 60 & M & Right & IB & C & B \\
\hline 25 & M & Left & IIB & B & A \\
\hline 25 & M & Right & IIB & B & A \\
\hline 31 & M & Left & IB & B & A \\
\hline 31 & M & Right & IB & C & B \\
\hline 30 & M & Left & IB & A & A \\
\hline
\end{tabular}

*The start of the curve of the superficial palmar arch and the apex were related to the Kaplan cardinal line. 
Table 6 Comparison between classifications

\begin{tabular}{|c|c|c|c|c|c|}
\hline Age & Gender & Hand & Jaschtschinski $^{2}$ & $\begin{array}{l}\text { Lippert } \\
\text { et } \mathrm{al}^{9}\end{array}$ & $\begin{array}{l}\text { Coleman } \\
\text { et } \mathrm{al}^{8}\end{array}$ \\
\hline 28 & $M$ & Right & ID & B1a & IB \\
\hline 48 & $M$ & Right & IIA & B2 & IIA \\
\hline 48 & M & Left & IA & $\mathrm{A} 1$ & IA \\
\hline 29 & $M$ & Left & ID & B1a & IB \\
\hline 60 & M & Right & ID & B1a & IB \\
\hline 25 & $M$ & Left & $\| A$ & B1b & IIB \\
\hline 25 & $M$ & Right & IIA & B1b & IIB \\
\hline 31 & $M$ & Left & ID & B1a & IB \\
\hline 31 & $M$ & Right & ID & B1a & IB \\
\hline 30 & $M$ & Left & ID & B1a & IB \\
\hline
\end{tabular}

Showing the results of the reclassified dissections with the three different classifications.

Table 7 Results by classification

\begin{tabular}{|c|c|c|c|c|c|}
\hline Jaschtschinski $^{2}$ & (n) & Lippert et $\mathrm{al}^{9}$ & (n) & $\begin{array}{l}\text { Coleman } \\
\text { et } \mathrm{al}^{8}\end{array}$ & (n) \\
\hline Complete IA & 1 & Complete A1 & 1 & IA & 1 \\
\hline Complete ID & 6 & $\begin{array}{l}\text { Incomplete } \\
\text { B1a }\end{array}$ & 6 & IB & 6 \\
\hline \multirow[t]{2}{*}{$\begin{array}{l}\text { Incomplete } \\
\text { IIA }\end{array}$} & 3 & $\begin{array}{l}\text { Incomplete } \\
\text { B1b }\end{array}$ & 2 & $\| \mathrm{A}$ & 1 \\
\hline & & $\begin{array}{l}\text { Incomplete } \\
\text { B2 }\end{array}$ & 1 & IIB & 2 \\
\hline
\end{tabular}

Showing the differences in the classification of the superficial palmar arch.

Table 8 Frequency of complete and incomplete superficial palmar arch and ulnar type depending on the classification used

\begin{tabular}{|c|c|c|c|}
\hline & $\begin{array}{l}\text { Jaschtschinski }{ }^{2} \\
\text { (n) }\end{array}$ & $\begin{array}{l}\text { Lippert } \\
\text { et } \mathrm{al}^{9}(\mathrm{n})\end{array}$ & $\begin{array}{l}\text { Coleman } \\
\text { et } \mathrm{al}^{8}(\mathrm{n})\end{array}$ \\
\hline $\begin{array}{l}\text { Complete } \\
\text { arch }\end{array}$ & 7 & 1 & 7 \\
\hline $\begin{array}{l}\text { Incomplete } \\
\text { arch }\end{array}$ & 3 & 9 & 3 \\
\hline Ulnar arch & 6 & 8 & 8 \\
\hline
\end{tabular}

*Ulnar palmar arch frequency is calculated based on the total number of dissections performed. Showing the differences in frequency in the type of superficial palmar arch, depending on the classification used.

percentage of ulnar arches. ${ }^{1,16}$ This is similar to what was found in the present study when the superficial palmar arches were reclassified.

There are multiple case reports of unusual superficial palmar arches, and they show racial differences in the frequency of the type of superficial palmar arch. In 1928, Adachi described differences in the vascular pattern of the hand in Japanese and American subjects. ${ }^{15}$ Other studies have also reported racial differences, particularly in the frequency of the superficial and deep palmar arch types, as well as of the subtypes and of the presence of a median artery. ${ }^{1}$
Skin references have been consistently sought in the anatomy of the surface of the hand to identify and maintain its vital neurovascular structures. One of these references is the Kaplan cardinal line. Currently, there is no consensus regarding the trajectory of the Kaplan cardinal line or its relationship with the deep structures of the hand. Relationships have been described with the motor branch of the median nerve, with the deep branch of the ulnar nerve, with the distal edge of the transverse carpal ligament, and with the superficial palmar arch. $^{20,21,25}$ Multiple anatomical studies have been performed, most taking into account the surgical limits to perform an open or endoscopic carpal tunnel release.

Panchal et al performed an anatomical study on 30 corpses, dissecting 60 hands, to describe the relationship of the intersection of the Kaplan cardinal line in its original description and of 2 longitudinal lines on the radial and ulnar edge of the ring finger with the superficial palmar arch. They found a distance of $10.2 \mathrm{~mm}$ from the distal edge of the incision to the superficial palmar arch. ${ }^{26}$

McLean et al performed an anatomical study on 48 fresh cadaveric hands in specimens between 50 and 75 years old. They found that the distance of the superficial palmar arch to the Kaplan cardinal line in its original description was $15.3 \pm 8.6 \mathrm{~mm}$. They also described the distance of the distal palmar crease from the wrist to the superficial palmar arch, with a distance of $51.8 \pm 7.56 \mathrm{~mm}$. They reported little variability and suggested that it could be a more reliable reference in locating the superficial palmar arch. ${ }^{25}$ In their 2005 study, Vella et al described a distance of $14 \pm 5 \mathrm{~mm}$ from the original Kaplan cardinal line to the superficial palmar arch. Using a second description of the Kaplan cardinal line from 1968, which places it from the palmar crease between the thumb and the index finger $2 \mathrm{~cm}$ from the pisiform bone, they found a distance of $11 \pm 4 \mathrm{~mm}$. They have also found that the distance of the superficial palmar arch to the other two descriptions of the Kaplan cardinal line (intersection with the hamate bone or with the pisiform bone) was greater by $18 \pm 4 \mathrm{~mm}$ and by $19 \pm 6 \mathrm{~mm}$, respectively. ${ }^{20}$

Kwiatkowska et al carried out an anatomical study in 2014 to establish the relation between the palmar creases and the deeper neurovascular structures of the hand. They found that the superficial palmar arch never crossed the proximal or the distal palmar crease. The average distance from the distal part of the arch to the thenar crease was $51 \mathrm{~mm}$; from the convex part of the arch, it was $72 \mathrm{~mm}$, and from the proximal part of the arch, it was $1.07 \mathrm{~cm} .{ }^{27}$ In this study, no distance measurements were made from the skin references or from the Kaplan cardinal line to the apex of the superficial palmar arch.

In this anatomical study of ten palmar arches, the superficial palmar arch types were classified according to the classification by Coleman et al. Seven of the palmar arches were complete and three were incomplete. Of these, the most common type was ulnar type IB (complete ulnar arch), which differs from most studies, except for the one carried out by Showri in India. ${ }^{21}$ Of the incomplete palmar arches, type IIB (ulnar supply only but with no supply to the index finger or to the thumb) was the most common. There were no superficial palmar arches with supply from the median artery. 
Table 9 Types of palmar arch literature review

\begin{tabular}{|c|c|c|c|c|c|}
\hline $\begin{array}{l}\text { Number of } \\
\text { dissections }\end{array}$ & Authors (Year) & $\begin{array}{l}\text { Complete } \\
\text { arch }\end{array}$ & Ulnar arch (LPB1a/JA4) & Incomplete & Classification used \\
\hline 200 & Jaschtschinski $(1987)^{2}$ & $68 \%$ & $38 \%$ (of complete) & $32 \%$ & New \\
\hline 200 & Adachi $(1928)^{15}$ & $\begin{array}{l}\text { Not } \\
\text { mentioned }\end{array}$ & $60.5 \%$ & Not mentioned & None \\
\hline 50 & Al Turk et al $(1983)^{23}$ & $84 \%$ & $2 \%$ & $58 \%$ & Jaschtschinski \\
\hline 650 & Coleman \& Anson $(1961)^{8}$ & $78.5 \%$ & $37 \%$ (of complete) & $21.5 \%$ & $\begin{array}{l}\text { New adaptation } \\
\text { of Jaschtschinski }\end{array}$ \\
\hline 200 & Lippert y Pabst $(1985)^{9}$ & $42 \%$ & $37 \%$ & $21 \%$ & New \\
\hline 220 & Ikeda et al $(1988)^{10}$ & $96.4 \%$ & $33.2 \%$ (of complete) & $3.6 \%$ & $\begin{array}{l}\text { New modification } \\
\text { of Jaschtschinski }\end{array}$ \\
\hline 50 & Jelicic et al $(1988)^{7,16}$ & $97 \%$ & Not mentioned & $3 \%$ & None \\
\hline 80 & Özkus et al (1998) ${ }^{11}$ & $78 \%$ & $17.5 \%$ (of complete) & $22 \%$ & None \\
\hline 45 & Gellman et al $(2001)^{5}$ & $84.5 \%$ & $31 \%$ (of complete) & $15.5 \%$ & Jaschtschinski \\
\hline 50 & Ruengsakulrach et al (2001) & $66 \%$ & Not mentioned & $24 \%$ & None \\
\hline 200 & Loukas et al $(2005)^{12}$ & $90 \%$ & $35 \%$ (of complete) & $10 \%$ & Coleman et al \\
\hline 50 & Bilge et al $(2006)^{3}$ & $83 \%$ & $14 \%$ (of complete) & $7 \%$ & Coleman et al \\
\hline 20 & Murat et al. $(2007)^{16}$ & $40 \%$ & $58.3 \%$ (of incomplete) & $60 \%$ & Lippert et al \\
\hline 25 & Omaña et al $(2007)^{16}$ & $56 \%$ & Not mentioned & $44 \%$ & Lippert et al \\
\hline 20 & Tagil et al. (2007) ${ }^{13}$ & $75 \%$ & $35 \%$ (of complete) & $25 \%$ & Coleman et al \\
\hline 30 & Bataineh et al. (2007) ${ }^{14,16}$ & $73 \%$ & $55 \%$ (of complete) & $27 \%$ & None \\
\hline 86 & Ottone et al $(2010)^{16,28}$ & $58 \%$ & 55\%(incomplete) & $42 \%$ & Lippert et al \\
\hline 60 & Suman et al $(2011)^{6}$ & $50 \%$ & Not specified & $50 \%$ & Not specified \\
\hline 702 & Feigl et al. $(2011)^{15}$ & $51.7 \%$ & $16.1 \%$ (of incomplete) & $32.2 \%$ & Lippert et al \\
\hline 100 & Joshi et al. $(2014)^{1}$ & $26 \%$ & $56 \%$ (of incomplete) & $74 \%$ & Lippert et al \\
\hline 92 & Jena $(2017)^{29}$ & $95.2 \%$ & $2.1 \%$ (of the total) & $4.8 \%$ & None \\
\hline
\end{tabular}

Adapted from: Joshi et al. (2014); Feigl et al. (2011); Arias-Hernández et al (2015). 1,15,16

Since the muscles of the thenar region were not lifted, the supply of a vessel from the deep palmar arch to the superficial palmar arch may have been overlooked. However, the classification by Coleman et al does not consider the deep ulnar arch as a subtype. In one case, the palmar arch was injured at the time of dissection, making it difficult to classify. It was classified as an incomplete palmar arch, since the superficial branch of the radial artery provided vascularity to the thumb and apparently to the radial border of the index finger, while the ulnar artery supplied the rest of the fingers. An anastomosis between the radial and ulnar arteries did not seem to be present.

After the reclassification with the other two classifications, there was no difference in the frequency of complete and incomplete superficial palm arches between the classifications by Jaschtschinski ${ }^{2}$ and by Coleman et $\mathrm{al}^{8}$ but a difference was observed in the subtypes. According to the classification by Jaschtschinski, ${ }^{2}$ six of the complete palmar arches corresponded to the ulnar type, while according to the classification by Coleman et $\mathrm{al}^{8}{ }^{8}$ eight of the total sample of palmar arches-five complete and three incomplete (Coleman et al include an ulnar variant in the incomplete type)were ulnar.
However, when using the classification by Lippert et al, ${ }^{9}$ nine of the palmar arches were incomplete, since the ulnar arch with no anastomosis is considered incomplete. According to this classification, eight of the incomplete palmar arches were ulnar.

This shows that there is a difference in the frequency of complete and incomplete arches depending on the classification used, especially if there is a high prevalence of ulnar palmar arches. This finding is comparable to that reported in the literature, and it is shown in - Table 9. If this is extrapolated to what is reported in the world literature, it is understandable that the frequency of ulnar palmar arches is not being estimated adequately and accurately.

At present, it is difficult to know with certainty the frequency of complete and incomplete superficial palmar arches and the dominance of the ulnar artery due to the wide variation of classifications reported in the literature that are variants of each other. Currently, a consensus must be reached, and it must be determined to what extent the presence of ulnar artery supply is considered a complete ulnar palmar arch. In this way, a true frequency of complete and incomplete superficial palmar arches can be established, including the ulnar supply in any of the categories. 
It is possible that the "classic" superficial palmar arch is not that much more common than an ulnar arch, and that the ulnar artery is much more important than it is acknowledged.

Regarding the relation between the Kaplan cardinal line and the superficial palmar arch in the present study, the start of the curve or the apex of the arch did not coincide with the line drawn towards the pisiform bone (line D) in any specimen. The start of the curve coincided with line $C$ in three specimens. In eight specimens, the apex coincided with line A (which corresponds to the original description of the Kaplan cardinal line). Although the sample size of the current study was too small to enable the establishment of a statistically significant correlation, there seems to be a tendency for the incomplete palmar arches to relate to line B at the start of the curve.

It can be concluded that the use of the Kaplan cardinal line as a safety limit during surgical procedures, such as open or endoscopic carpal tunnel release, can be useful if it is drawn towards the pisiform bone. This avoids the superficial palmar arch. The apex of the arch will be close to the proximal palmar crease, but it is likely that it will never reach it. If one wants to identify the superficial palmar arch, the original description of the Kaplan cardinal line is preferable.

The strengths of the present study are that it is the first anatomical study on superficial palmar arches conducted in Mexico and that no other study has attempted to relate the type of palmar arch with a specific description of the Kaplan cardinal line.

The weaknesses of the present study are: limited sample size, limited dissection, lack of polymer use in all specimens, lack of optical magnification during dissections to identify deep vessels that supply the superficial palmar arch, the correlation of the beginning of the curve of the superficial palmar arch with the Kaplan cardinal line and not with the apex. The distance from the apex of the superficial palmar arch to the Kaplan cardinal line (regarding any of its variants) could be described; the height of each arch, depending on its type and subtype, could be described and related to superficial markers of the palm of the hand.

More specimens whose accurate ancestry is known are needed to establish a statistically significant pattern of hand vascularity in the Mexican population. It is assumed that the cadavers are from the Mexican population, and it would seem that there is a greater frequency of ulnar dominant superficial palmar arches in our population. However, as the specimens are anonymous with unknown ancestry, this presumption can lead to incorrect conclusions. It would be interesting to know the hand dominance of the specimens to try to establish a relationship between hand dominance and the type of palmar arch. Since the thenar muscles were not elevated, there may have been errors in classifying the superficial palmar arch as incomplete if the vascular supply originated from the deep palmar arch and was not observed.

Finally, dynamic flow studies should be carried out to determine if the morphology of the superficial palmar arch correlates with hand supply and if the minor arteries are able to perform the function of the main arteries.

\section{Conclusion}

There is a great variability in the anatomy of the superficial palmar arch that has been recognized since the $19^{\text {th }}$ century. There are multiple classifications to describe the superficial palmar arch and there is no consensus on what constitutes a complete superficial palmar arch or an incomplete palmar arch. Depending on the classification used, the frequency of the superficial palmar arch type changes significantly. Therefore, a consensus in the nomenclature is required and a single classification must be established. Racial differences have been observed in the superficial palmar arch types, although they are not well documented.

The present study found a greater frequency of complete superficial palmar arches than incomplete palmar arches with ulnar dominant supply (both complete and incomplete). The Kaplan cardinal line can act as a safety line to avoid the superficial palmar arch if it is drawn towards the pisiform bone.

It is relevant for the hand surgeon, for the vascular surgeon or for any interventional physician to understand the variability of vascular patterns when planning invasive procedures or performing reconstructive surgeries. In traumatic pathology, the hand surgeon must understand the variants of the superficial palmar arch to be able to perform the appropriate reconstructions. If possible, before performing scheduled invasive procedures, imaging studies (Doppler ultrasound or arteriography) should be performed to classify the superficial palmar arch and avoid compromising the vascularity of the hand.

\section{Conflicts of Interest}

The authors have no conflicts of interest to declare.

\section{References}

1 Joshi SB, Vatsalaswamy P, Bahetee BH. Variation in formation of superficial palmar arches with clinical implications. J Clin Diagn Res 2014;8(04):AC06-AC09

2 Jaschtschinski SN. Morphologie und Topographie des Arcus volaris sublimis und profundus des Menschen. Anat Hefte 1897;7:161-188

3 Bilge O, Pinar Y, Ozer MA, Gövsa F. A morphometric study on the superficial palmar arch of the hand. Surg Radiol Anat 2006;28 (04):343-350

4 Takkallapalli A, Kalbande S, Dombe D, Krishnamurthy A, Neelee J. Variations in the formation of superficial palmar arch and its clinical significance in hand surgeries. Int J Biol Med Res 2011;2 (02):543-546

5 Gellman H, Botte MJ, Shankwiler J, Gelberman RH. Arterial patterns of the deep and superficial palmar arches. Clin Orthop Relat Res 2001;(383):41-46

6 Suman U, Jayanthi KS. A study of complete superficial palmar arches formed entirely by ulnar artery. J Anat Soc India 2011;60 (02):199-201

7 Jelicic N, Gajisin S, Zbrodowski A. Arcus palmaris superficialis. Acta Anat (Basel) 1988;132(03):187-190

8 Coleman SS, Anson BJ. Arterial patterns in the hand based upon a study of 650 specimens. Surg Gynecol Obstet 1961;113:409-424

9 Lippert H, Pabst R. 1985 In: Bergmann JF (Ed.), Arterial variations in man. München: Urban \& Schwarzenberg; 71-77

10 Ikeda A, Ugawa A, Kazihara Y, Hamada N. Arterial patterns in the hand based on a three-dimensional analysis of 220 cadaver hands. J Hand Surg Am 1988;13(04):501-509 
11 Özkus K, Peştelmaci T, Soyluoğlu AI, Akkin SM, Özkus HI. Variations of the superficial palmar arch. Folia Morphol (Warsz) 1998; 57(03):251-255

12 Loukas M, Holdman D, Holdman S. Anatomical variations of the superficial and deep palmar arches. Folia Morphol (Warsz) 2005; 64(02):78-83

13 Tagil SM, Cicekcibasi AE, Gün TC, Büyükmumcu M, Salbacak A. Variations and clinical importance of the superficial palmar arch. SDÜ Tip Fak. Derg. 2007;14(02):11-16

14 Bataineh ZM, Habbal O, Moqattash ST. Variations in the superficial palmar arch of the hand. Ital J Anat Embryol 2009;114(01):11-20

15 Feigl GC, Petrac M, Pixner T, Ulz H, Mörth C, Dreu M. The superficial palmar arch and median artery as an example of misleading results due to a small number of investigated specimens or the use of different classifications. Ann Anat 2012;194(04):389-395

16 Arias Hernández A, Peñaloza JE, Ballesteros LE. Arco palmar superficial: anatomía e implicaciones clínicas. Rev Med UIS 2015;28(03):363-369

17 Kaplan EB. Surface anatomy of the hand and the wrist. In: Spinner E, ed. Functional and surgical anatomy of the hand. Philadelphia: J.B. Lippincott Co; 1953:227-231

18 Kaplan EB. Surface anatomy of the hand and the wrist. In: Spinner $E$, ed. Functional and surgical anatomy of the hand. 2nd ed Philadelphia: J.B. Lippincott Co; 1965:265-270

19 Kaplan EB. Guide lines to deep structures and dynamics of intrinsic muscles of the hand. Surg Clin North Am 1968;48(05): 993-1002
20 Vella JC, Hartigan BJ, Stern PJ. Kaplan's cardinal line. J Hand Surg Am 2006;31(06):912-918

21 Showri R, Senthilkumar SA. Study on ulnar dominant complete superficial palmar arch. Int J Anat Res 2016;4(03):2587-2589

22 Earley MJ. The arterial supply of the thumb, first web and index finger and its surgical application. J Hand Surg [Br] 1986;11(02): 163-174

23 Al-Turk M, Metcalf WK. A study of the superficial palmar arteries using the Doppler Ultrasonic Flowmeter. J Anat 1984; 138(Pt 1):27-32

24 Patnaik VVG, Kalsey G. SinglaRajan K. Palmar Arterial Arches- A Morphological Study. J Anat Soc India 2002;51(02):187-193

25 McLean KM, Sacks JM, Kuo YR, Wollstein R, Rubin JP, Lee WP. Anatomical landmarks to the superficial and deep palmar arches. Plast Reconstr Surg 2008;121(01):181-185

26 Panchal AP, Trzeciak MA. The Clinical Application of Kaplan's Cardinal Line as a Surface Marker for the Superficial Palmar Arch. Hand (N Y) 2010;5(02):155-159

27 Kwiatkowska M, Jakutowicz T, Ciszek B, Czubak J. Can palmar creases serve as landmarks for the deeper neuro-vascular structures? Surg Radiol Anat 2014;36(05):495-501

28 Ottone NE, Prum N, Dominguez M, et al. Analysis and clinical importance of superficial arterial palmar irrigation and its variants over 86 cases. Int J Morphol 2010;28(01):157-164

29 Jena S, Arora G, Sadananda R, Sahu S, Tudu J. A study on morphological variants of human superficial palmar arch and their clinical importance. Sch J App Med Sci 2017;5(3C):867-872 